\title{
LIQUEFIED NATURAL GAS TENDER CRASHWORTHINESS IN TRAIN-TO-TRAIN COLLISIONS
}

\author{
David Tyrell \\ Volpe National Transportation Systems Center \\ United States Department of Transportation \\ Cambridge, Massachusetts, USA
}

\section{ABSTRACT}

Research to facilitate industry efforts to safely use natural gas as a locomotive fuel is being directed by the Federal Railroad Administration's (FRA's) Office of Research, Development, and Technology. This research is being conducted cooperatively with the Association of American Railroads (AAR). The research results are being shared with the AAR's Natural Gas Fuel Tender Technical Advisory Group (NGFT TAG), which includes AAR, Member Railroads, and FRA, with support from ARA and Volpe Center. The NGFT TAG is developing industry requirements, including crashworthiness requirements, for revenue-service natural gas fuel tenders.

Five accident scenarios have been drafted by the NGFT TAG: a train-to-train collision, a grade-crossing collision, rollover, shell impact, and head impact. Each scenario includes a description of the equipment, the impact conditions, and the prescribed outcome. Conceptually, these tender scenarios parallel the scenarios described in 49 CFR Part 229 Appendix E for locomotive crashworthiness.

The focus of the NGFT TAG discussions has expanded to include alternative static requirements. Conceptually, the tender static requirements parallel the requirements for locomotive crashworthiness in AAR S-580. Requirements in S-580 for locomotive structure include static load capacities, material properties, and material thicknesses. For conventionallydesigned locomotives, meeting the static requirements of S-580 is accepted as meeting the dynamic requirements of Appendix E. The tender static requirements under development are intended to provide the same level of crashworthiness as the previously proposed dynamic requirements.

The primary advantage of static crashworthiness requirements is that compliance can be shown with classical closed-form engineering analyses. A disadvantage is that design features are presumed, such as the inclusion and location of collision posts in a conventional locomotive design. Design features are not presumed in dynamic crashworthiness requirements; however, compliance must be shown with a design-specific validated computer simulation model. So while dynamic requirements allow for a wide range of design approaches, showing compliance often requires extensive effort.

This paper focuses on technical information to help support development of alternative static requirements for the train-totrain collision scenario. The goal of the static requirements is to provide the same level of crashworthiness as the dynamic requirements under discussion by the NGFT TAG. Tender features capable of providing the desired level of performance are proposed. These features have been selected such that a tender with these features would be crashworthy-compatible with a wide range of new and existing locomotive structural designs.

\section{INTRODUCTION}

The North American rail industry is developing the technology to reliably and safely use LNG as a locomotive fuel. LNG is a cryogenic liquid, and about two gallons of LNG is needed for a locomotive to travel the same distance as it can on one gallon of diesel fuel [1]. Consequently, LNG fuel tenders are being developed to carry sufficient fuel for the desired locomotive operating range and to handle the cryogenic aspects of LNG.

FRA's Office of Research, Development, and Technology is supporting research to address the safety aspects of using LNG as a locomotive fuel throughout the North American general railroad system. There are many safety considerations with the transportation, storage, delivery, and use of LNG as a locomotive fuel. One consideration is the potential for an accident and consequent spill. Accidents with highway vehicles can occur at 1

This material is declared a work of the U.S. Government and is not subject to copyright protection in the United States. Approved for public release; distribution is unlimited. 
grade-crossings, trains can derail due to track and equipment defects, and trains can collide. Even when Positive Train Control systems are fully in place, manual train operation will be allowed on main line track for train speeds up to $20 \mathrm{mph}$. Consequently, there will remain a potential for a train-to-train collision with a 40 mph closing speed [2].

\section{Approaches for Crashworthiness Standards}

There are three approaches that have been used for rail equipment crashworthiness standards: design standards, performance standards, and hybrid standards. There are tradeoffs among the different approaches, most notably in complexity of showing compliance and in flexibly allowing alternative design strategies.

Design standard - strength based requirements that are intended to be effective in the range of expected accident and incident conditions. Compliance is typically demonstrated with classical manual engineering calculations and non-destructive tests. Design standards often implicitly assume particular design features, such as buff stops. Examples of design standards include the AAR S-580 locomotive crashworthiness standard [3], the AAR S-5506 fuel tank integrity standard [4], and the FRA Tier I conventional speed passenger equipment crashworthiness regulations in 49 CFR 238 [5].

Performance standard - scenario-based requirements that are intended to bound the range of potential accidents and incidents. Compliance is typically demonstrated with computer simulations, non-destructive car tests, and destructive component tests. Performance standards permit a wide range of design approaches. Examples of performance standards include 49 CFR 229 Appendix E Locomotive Crashworthiness regulations [6] and 49 CFR 238 Appendix F Cab Car End Structure regulations [7].

Hybrid standard - intended to combine the most desirable aspects of the design- and performance-based standards. Hybrid standards typically include critical scenarios and a reduced set of minimum structural strength standards. The structural strength standards are often written to allow flexibility in location of the application of the load. Computer modeling may be used to extrapolate testing. For example, the draft alternative Tier I passenger regulations require testing the carbody with a relatively low compressive end load without permanent deformation, and require extrapolation to the relatively high crippling load with computer simulation. Permanent deformation is simulated with this approach, but no actual carbodies need to be destroyed. Validation of the computer model with the non-destructive test results is critical with this approach. Examples of hybrid rail equipment crashworthiness standards include the Tier II high-speed mixed-service passenger train crashworthiness regulations and the European standards for street cars, transit cars, commuter, and intercity trains EN12663 and EN15227 [8, 9].

For LNG tenders, alternative performance and design standards are under discussion with the AAR's NGFT TAG. Five scenarios have been drafted $[10,11]$ and discussed. Alternative design standards are being developed for each of the five scenarios. This paper describes some of the research results intended to support development of alternative design standards to the draft performance standards associated with a train-totrain collision scenario.

\section{TRAIN-TO-TRAIN COLLISION SCENARIO}

Figure 1 shows a schematic of scenario 1, the train-to-train collision scenario. In this scenario, a consist initially travelling at $22.5 \mathrm{mph}$ and made up of a locomotive-fuel tender-locomotive collides with a fixed rigid barrier. The collision occurs on level tangent track. The idealized scenario takes advantage of symmetry, with the fixed barrier. This allows the focus to be on the behavior of the tender, and minimizes the distraction of the colliding interface.

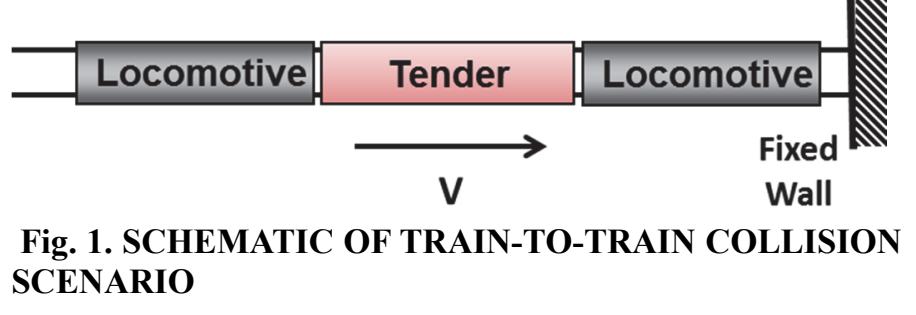

This scenario is derived from an accident that occurred in Two Harbors, Minnesota on September 30, 2010 [12]. In this accident, two trains collided at a closing speed of $42 \mathrm{mph}$. Both trains were led by three locomotives. The locomotives all remained essentially in-line, override did not occur, and all of the crew members survived. For the idealized scenario, symmetry has been used, and the speed has been increased.

\section{CRASHWORTHINESS DESIGN STRATEGY}

There are several strategies that could potentially be used to develop a tender design that is sufficiently crashworthy to survive the scenario without loss of fuel. In the Two Harbors accident, five of the six locomotives were of the same design. The sixth locomotive was a trailing unit with the same underframe design as the other five. The structural and inertial similarities likely helped the locomotives remain inline during the collision. The center-of-gravity height and underframe construction of the tender are likely to differ from those of the locomotives. Structural and inertial differences between the tender and locomotives may tend to make their interfaces less stable in a collision than the interfaces of the similar locomotives. Consequences from other locomotive accidents suggest such structural and inertial differences may lead to override or lateral buckling. A crashworthiness strategy that allows the locomotive to tender interface to remain stable under asymmetric collision conditions appears to be desirable. For this paper, the crashworthiness design strategy selected for protecting the tender is Crash Energy Management (CEM). Even though 'Energy' is part of the name, this strategy emphasizes managing the load path between cars. CEM entails three principal functions:

1. Strong foundation

2. Managed load path

3. Distributed energy absorption

CEM essentially builds on the traditional railroad approach to locomotive and rail equipment crashworthiness. The traditional railroad approach to crashworthiness is to build a strong underframe, which can sustain a high buff load without permanent deformation [13]. CEM adds features which manage the load path, to inhibit override of colliding and coupled equipment, as well as lateral buckling. These features help assure that the strong underframe is loaded in a favorable manner, so that it can sustain a high longitudinal load throughout

This material is declared a work of the U.S. Government and is not subject to copyright protection in the United States. Approved for public release; distribution is unlimited. 
a train-to-train collision. By loading the underframe this way, such features also help inhibit crippling and collapse of the underframe. Energy absorbing features used at the ends of cars also help assure that structural deformation is appropriately distributed and not catastrophically focused on one piece of equipment.

For rail passenger equipment, CEM features have been used to increase crashworthiness performance significantly. For a cab car-to-locomotive collision of two passenger trains, equipment with CEM features can protect the passengers and crew for twice the collision speed as conventional equipment [14]. The performance of passenger equipment with CEM features has been measured and analyzed in detail $[15,16,17]$.

This paper includes simplified engineering analysis of CEM features on LNG tenders. Engineering design, detailed analysis, and test efforts, similar to those conducted for passenger equipment, are likely to be essential to develop CEM features for LNG tenders that are service and crashworthiness compatible with freight locomotives.

\section{PROPOSED TENDER DESIGN FEATURES}

For this paper and discussion purposes, all of the CEM features for managing the load path and distributing the energy absorption are constrained to be on the tender. By putting all of the crashworthiness features on the tender, the tender can then be crashworthiness compatible with a wide range of existing and new locomotive designs. For this paper and discussion purposes, a modified DOT 113 tank car design was selected as the platform for the proposed CEM tender design. DOT 113 cars are doublehulled tank-within-tank designs, and are designed to transport LNG and other cryogenic commodities. The inner tank looks much the same as the outer tank, but has a smaller diameter and shorter length. These CEM features may also be adapted for other designs, such as well cars. Well cars, with smaller-capacity removable tanks, are being considered by some industry members as the basis for LNG tenders [18].

Figure 2 schematically illustrates the tender design features intended to manage the load and the load path in the event of a train-to-train collision. There are a total of five CEM features: strong underframe, pushback coupler, deepened bell-mouth, deformable anti-climber, and primary energy absorber. These features are incorporated into both ends of the tender. Three of the features are intended to manage the load path: the pushback coupler, the enlarged bellmouth, and the deformable anticlimber. These features may also absorb energy when they are activated under train-to-train collision conditions. In combination with the primary energy absorber, they also help distribute energy absorption to both ends of the tender. These features are not part of the conventional DOT 113 cars designed for transporting cryogenic commodities.

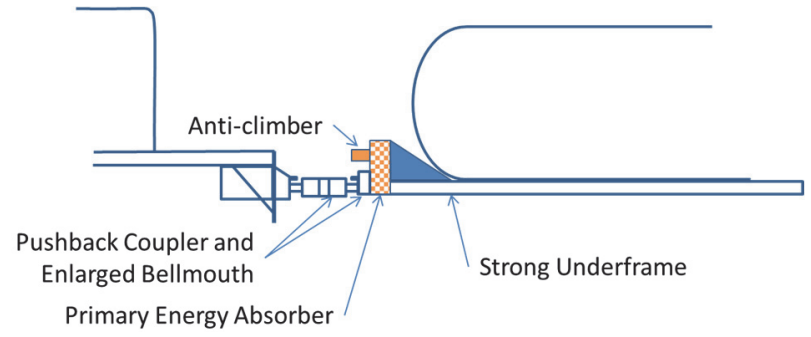

Fig. 2. SCHEMATIC OF TENDER CRASHWORTHINESS
Under collision conditions, when the longitudinal force is high, the five design features are intended to function in concert and manage the load path between the tender and the locomotive. Figure 3 illustrates how the features are intended to perform. In the first step, the load path is along the line of draft and through the couplers. In the second step, when a sufficiently high longitudinal load is transmitted by the locomotive, the tender's pushback coupler triggers and retracts into the deepened bellmouth. For the third step, the load path has moved to the anti-climber and the anti-climber crushes. In the fourth step, the primary energy absorber crushes. Throughout these steps, the strong underframe is needed for the proper functioning of the other features. Energy is absorbed at the front and rear of the tender, when features deform.

Each feature has key design requirements necessary to achieve the sequence of events shown in Figure 3. The pushback coupler must trigger before the onset of override or lateral buckling. The geometry of the deepened bellmouth must sufficiently accommodate the pushback coupler and locomotive coupler head to allow transfer of the load path to the anti-climber. The anti-climber must transmit high longitudinal loads, preserve the vertical and lateral load paths, and its geometry must accommodate a range of locomotives. The primary energy absorber, in concert with the pushback coupler and the deformable anti-climber must absorb collision energy. Finally, the crippling strength for the underframe must be sufficiently high, so that the underframe does not collapse as the other features are exercised.

1. Locomotive and tender coupled, load path through line-of-draft

2. PBC triggers, absorbs energy; deepened bellmouth allows transfer of load path to anti-climber

3. Anti-climber crushes; load path through tender and locomotive end structures

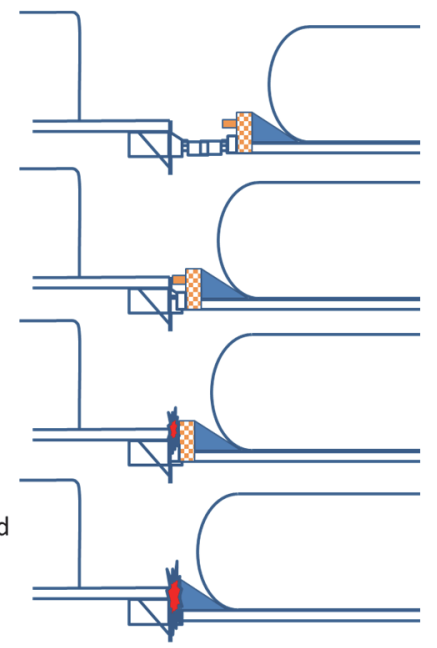

Fig. 3. FUNCTION OF TENDER CRASHWORTHINESS DESIGN FEATURES

\section{STRONG UNDERFRAME}

The underframe, in combination with the outer tank, of the tender acts as the foundation for all other crashworthiness features. The pushback coupler, the anti-climber, and the primary energy absorber all need to be supported by a sound structure. The underframe/outer tank must be capable of accepting the loads from these components at their locations without crippling and collapse. In addition, when the coupler, anti-climber, and absorber have all been exhausted, the underframe/outer tank must also be capable of transferring load from the lead locomotive to the trailing locomotive. As described in more detail in Appendix A, the strength of the tender underframe is chosen to be as strong as a locomotive underframe

This material is declared a work of the U.S. Government and is not subject to copyright protection in the United States. Approved for public release; distribution is unlimited. 
for the same loading condition. When the longitudinal load is applied at the height of the tender anti-climber, then the locomotive underframe crippling strength is interpolated to be 4,500 kips. Accordingly, the tender underframe/outer tank is required to have a crippling strength of at least 4,500 kips for a longitudinal load applied at the anti-climber height.

\section{PUSHBACK COUPLER AND DEEPENED BELLMOUTH}

In normal service, the pushback coupler functions the same as a conventional coupler. Like a conventional coupler, the tender coupler must be able to sustain a 4 mph coupling without damage or triggering. When a sufficiently high longitudinal collision load is applied, the pushback coupler retracts and transfers the load path from line-of-draft to the anti-climber. While retracting, the pushback coupler may also absorb energy; however its primary function is in managing the load path. As described in further detail in Appendix B, a pushback coupler trigger load of 1,200 kips is sufficient to inhibit override and lateral buckling in most circumstances.

The deepened bellmouth and the pushback coupler are integrated and work together. In service, the bellmouth functions like a conventional bellmouth with coupler carrier. For high longitudinal loads, the deepened bellmouth provides sufficient space to accommodate the pushback coupler when it retracts. The bellmouth and coupler carrier must be designed such that the couplers remain coupled and the lifting pin and associated safety appliances are not engaged. Figure 4 shows an example pushback coupler and deepened bellmouth, developed for passenger equipment.

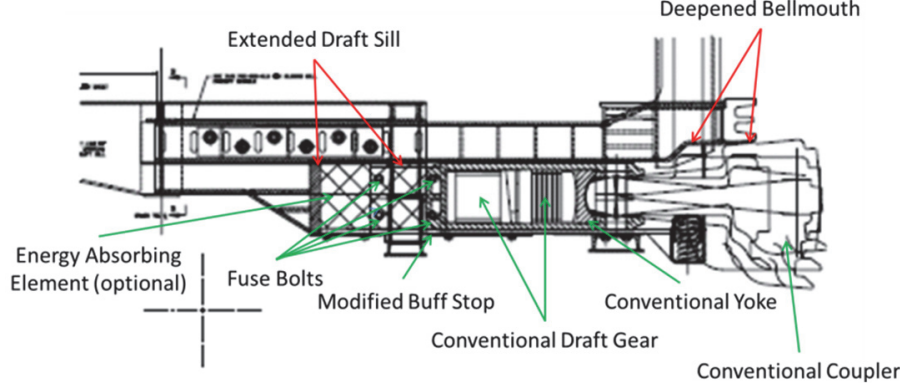

Fig. 4. EXAMPLE PUSHBACK COUPLER AND DEEPENED BELLMOUTH [14]

The pushback coupler and deepened bellmouth shown in Figure 4 are from the FRA prototype CEM cab car [15]. This pushback coupler design includes a conventional coupler and draft gear. The buff stops, which support the draft gear during normal operation, have been modified to fail at a prescribed impact load. These features were tested as part of the CEM trainto-train test $[16,17]$. In this test, a CEM cab car led passenger train collided with a conventional locomotive-led passenger train at $30 \mathrm{mph}$. A conventional passenger locomotive was in the trailing position in the CEM cab car led train, coupled with a second CEM cab car. Figure 5 shows post-test photographs of the trailing locomotive and coupled cab car. The pushback coupler is fully retracted into the deepened bellmouth, and the conventional coupler from the locomotive extends partially into the deepened bellmouth.

Application of the concept illustrated in Figure 4 to tender crashworthiness design is likely to result in different design details. The trigger load for retraction of the pushback coupler is likely to be significantly higher for the tender. The buff stop geometry for locomotives is different than for cab cars, which is likely to lead to detail design differences. The concept allows the inclusion of conventional alignment-controlled locomotive draft gear. Space limitations on the locomotive may inhibit the energy absorption capacity of the pushback coupler when a conventional draft gear is used; other elements, such as the deformable anti-climber and primary energy absorber, may be used to provide the needed energy absorption capacity. Engineering design, analysis, and test efforts, similar to those conducted for passenger equipment [15, 16, 17], may be necessary to develop prototype and service CEM features for LNG tenders that are service and crashworthiness compatible with existing freight locomotives.

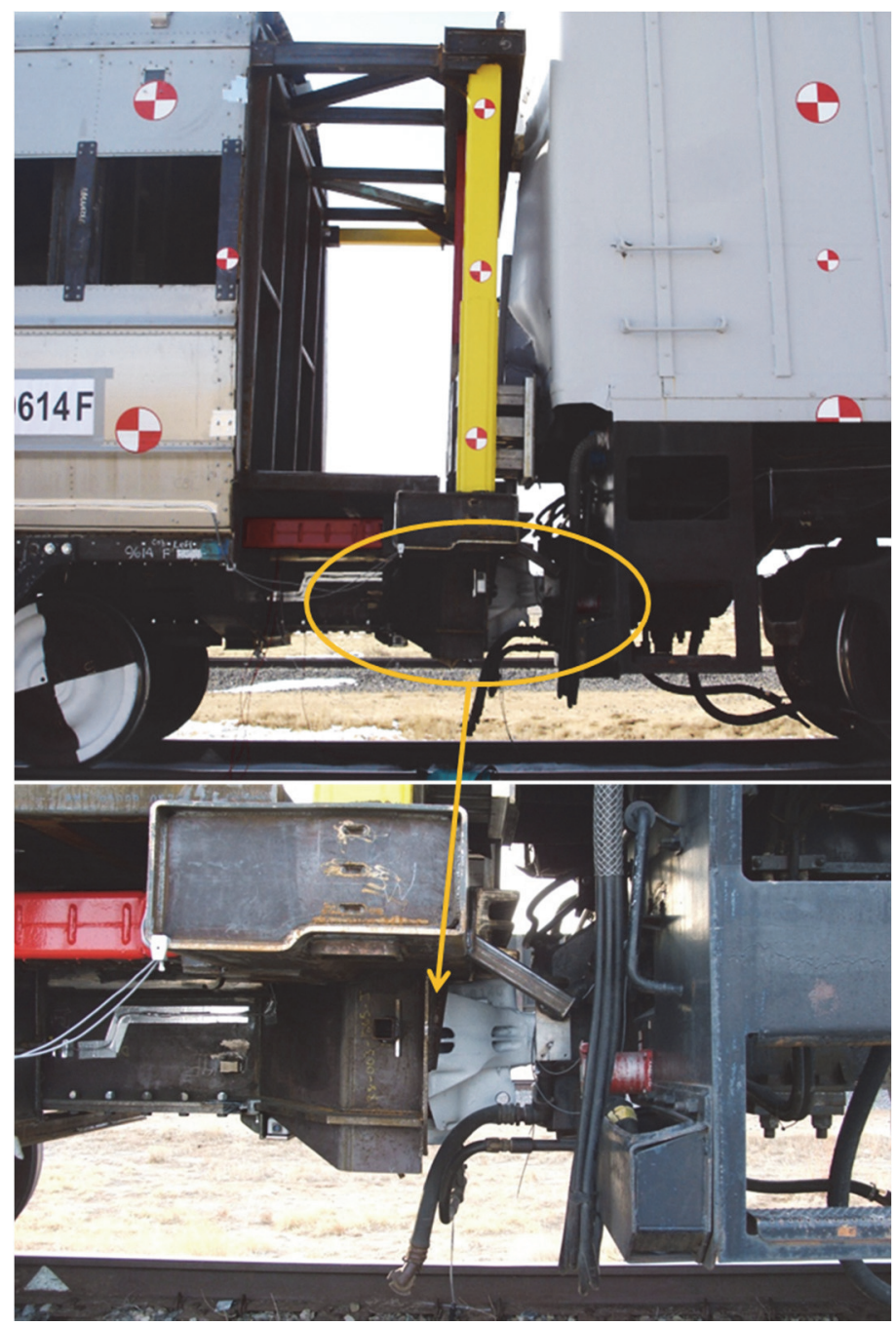

Fig. 5. TESTED PERFORMANCE OF EXAMPLE PUSHBACK COUPLER AND DEEPENED BELLMOUTH

\section{DEFORMABLE ANTI-CLIMBER}

The deformable anti-climber is intended to transfer the load path between the locomotive and tender from the line of draft to the collision load path. While transferring the load path, the deformable anti-climber is expected to maintain vertical and lateral load carrying capacity as it crushes longitudinally. The load is to be applied over a wide area, to help assure stable load transfer between the tender and locomotive. Such an anticlimber may be designed to meet the same space constraints as a conventional locomotive anti-climber [19]. Anti-climber space

This material is declared a work of the U.S. Government and is not subject to copyright protection in the United States. Approved for public release; distribution is unlimited. 
is constrained by the space needed for hoses, cables, safety appliances and other operationally-essential features. If needs be, the deformable anti-climber may also be designed to meet conventional strength-based requirements. The strength-based and deformation-based requirements can both be met by using thinner and more ductile material than is traditionally used in conventional locomotive anti-climbers. There are a number of passenger locomotives with deformable anti-climbers in service and in development. These passenger locomotives include the Amtrak HHP, Amtrak ACS-64, Caltrain/IDOT ACR-44, and the Metrolink F125. Figure 6 shows a prototype deformable anticlimber developed by FRA. This anti-climber meets current static requirements [3], can crush and absorb energy while maintaining vertical and lateral load paths, and is intended to be crashworthiness compatible with a wide range of passenger and freight equipment [19, 20, 21].

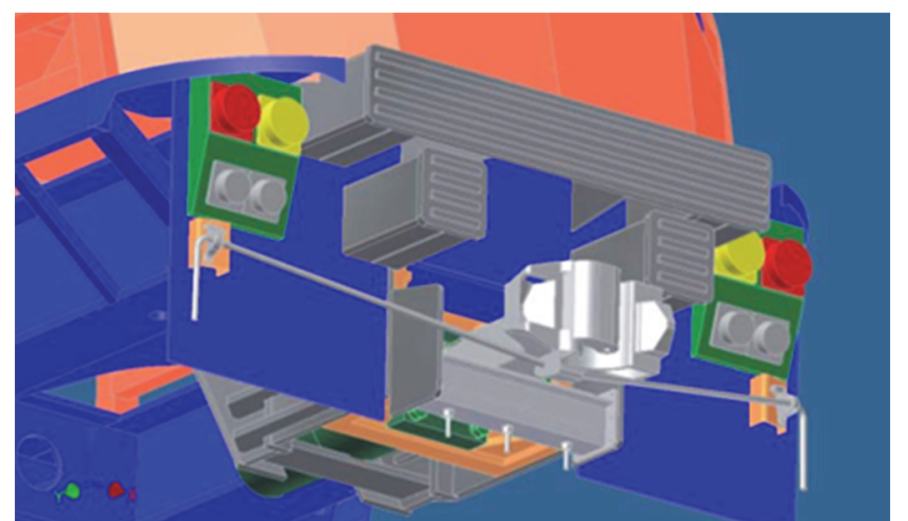

Fig. 6. FRA PROTOTYPE DEFORMABLE ANTICLIMBER

FRA also developed a cab car deformable anti-climber design that maintains vertical and lateral load path and also meets traditional strength-based requirements [15, 17]. This deformable anti-climber was also tested as part of the CEM trainto-train test. Figure 7 shows the tested performance of this deformable anti-climber. This anti-climber was effective in transferring the load path from the line-of-draft to the end frames of the cab car and locomotive.

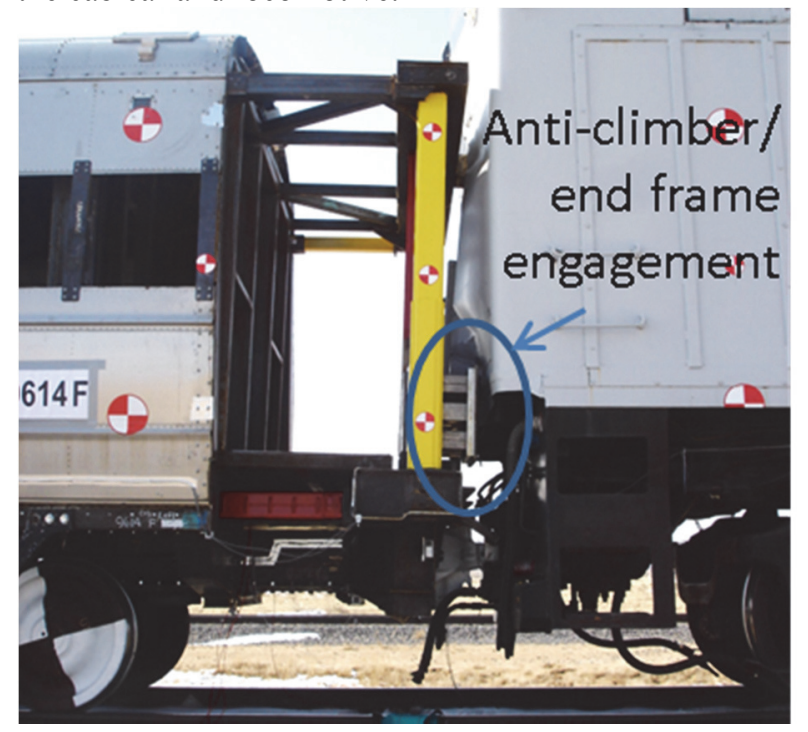

Fig. 7. TESTED PERFORMANCE OF PROTOTYPE CEM CAB CAR DEFORMABLE ANTI-CLIMBER

\section{PRIMARY ENERGY ABSORBER}

Ideally, each crush zone absorbs the initial kinetic energy of the car behind it [22]. For the collision scenario shown in Figure 1 , the lead end of the locomotive would ideally absorb its own energy with deformation of the end structure against the wall. The collision energy of the tender would be absorbed by the tender's leading end crush zone, and the collision energy of the trailing locomotive would be absorbed by the tender's trailing end crush zone. Pragmatically, leading crush zones absorb somewhat more and trailing crush zones absorb somewhat less. Each crush of the tender may be estimated to absorb about half of the combined initial kinetic energy of the tender and trailing locomotive. That energy is:

$$
E \cong \frac{1}{2}\left[\frac{\left(M_{L}+M_{T}\right)}{2}\right] V^{2}
$$

Where

$\mathrm{M}_{\mathrm{L}}$ is the mass of the locomotive,

$\mathrm{M}_{\mathrm{T}}$ is the mass of the tender, and

$\mathrm{V}$ is the initial velocity of the tender and locomotive. For a 286 kip tender and 415 kip locomotive initially travelling at $22.5 \mathrm{mph}$, the average kinetic energy is 5.9 million $\mathrm{ft}-\mathrm{lbs}$. In addition to absorbing energy, the maximum force exerted by the primary energy absorber must be less than the crippling load of the tender underframe. There are numerous approaches which have been used to design primary energy absorbers for passenger equipment $[23,24,25]$. Engineering design, detailed analysis, and test efforts would be needed to apply such primary energy absorber design approaches to LNG fuel tenders intended for freight service.

\section{SIMPLIFIED ANALYSES}

The performance of the proposed design strategy in the target collision scenario, shown schematically in Figure 1, has been evaluated with a simplified one-dimensional train collision dynamics model. Such models include discrete masses coupled with non-linear springs (force/crush characteristics). The masses can move longitudinally, but no vertical or horizontal motion is allowed. Coupling has also been evaluated with a onedimensional model, but with a different scenario: a single moving car impacting a single standing car. Coupling takes place at a relatively low speed, while the collision takes place at a relatively high speed. The displacements between the cars is much greater in the collision scenario than in the coupling scenario.

Essential to both collision and coupling analyses is the force/crush characteristic between the tender and locomotive masses. Figure 8 shows a force/crush characteristic which meets all of the key requirements summarized in Table 1. Both the longitudinal force between the locomotive and tender and the locomotive and the wall are plotted. For the locomotive-wall curve, crush is the distance from the locomotive center of gravity to the fixed and rigid wall. Since the wall is rigid, crush is essentially the reduction in length of the locomotive. For the tender-locomotive curve, crush is the distance between the centers of gravity of the tender and locomotive. Since all of the deformable elements are on the tender, crush is essentially the reduction in length of the tender.

This material is declared a work of the U.S. Government and is not subject to copyright protection in the United States. Approved for public release; distribution is unlimited. 


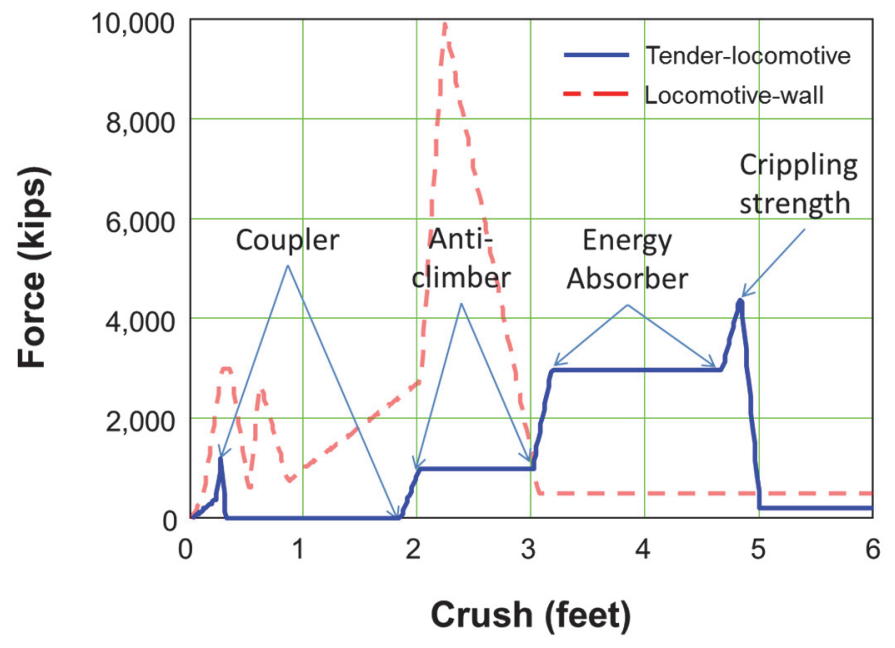

Fig. 8. TESTED PERFORMANCE OF PROTOTYPE CEM CAB CAR DEFORMABLE ANTI-CLIMBER

The initial portion of the tender-locomotive characteristic shown in Figure 8 represents the draft gear buff stiffness input into the model. Both the locomotive and tender are assumed to be equipped with alignment controlled NC390 draft gear [26]. This stiffness is for the coupled locomotive and tender. Displacement is the change in distance between the centers of gravity of the locomotive and tender. The coupled draft gears have a working range of about 3 inches, after which they bottom out. The force at bottoming out is 1,000 kips. The draft gears are much stiffer after bottoming out, with the flexible rubber elements fully compressed. After bottoming out the draft gear, the force increases to 1,200 kips with small additional displacement and the tender buff stop shear bolts are triggered. Once the shear bolts are triggered, the longitudinal force drops to zero, until the tender's deformable anti-climber is engaged. For these analyses, the shear-back coupler has no energy absorption capacity. Energy absorption could potentially be added to the shear back coupler. Once the tender anti-climber is engaged, the force increases to 1,000 kips. This force level is maintained until the primary energy absorber is engaged. Once the primary energy absorber is engaged, the force increases to 3,000 kips. The force/crush characteristic peaks at 4,000 kips, the crippling strength of the underframe/outer tank. The primary energy absorber is fully crushed with 6.0 million ft-lbs of energy, slightly more than the 5.9 million $\mathrm{ft}-\mathrm{lbs}$ calculated with equation (1). 6.6 million $\mathrm{ft}-\mathrm{lbs}$ is needed to cripple the tender underframe/tank, providing additional margin.

\section{SCENARIO PERFORMANCE}

Figure 9 shows the velocity time-histories for the lead locomotive, tender, and trailing locomotive, calculated with the one-dimensional lumped-parameter model. The tender is fully loaded, and weighs $286 \mathrm{kips}$ in this simulation. The lead locomotive comes to a stop in just over 0.1 seconds. After about 0.25 seconds, the tender has stopped, and the trailing locomotive stops after about 0.45 seconds. Each piece of equipment goes through the impact almost individually. The tender and trailing locomotive only slow down by about $1 \mathrm{mph}$ while the lead locomotive is crushing. The trailing locomotive slows down by another $1 \mathrm{mph}$ while the lead end of the tender is crushing.

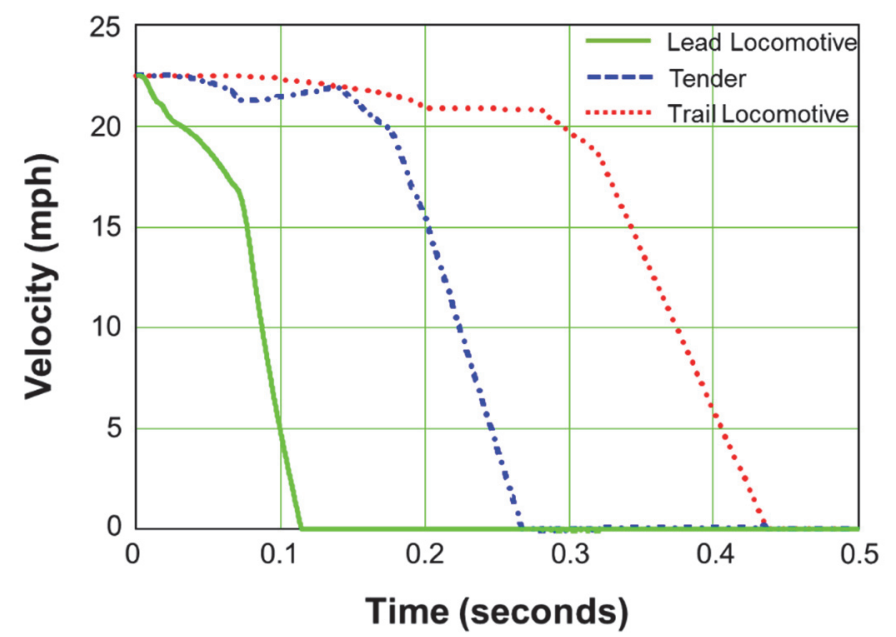

Fig. 9. VELOCITY TIME HISTORIES FOR EQUIPMENT IN TRAIN-TO-TRAIN COLLISION SCENARIO

Figure 10 shows the crush time-history for the equipment in the train-to-train collision scenario. Crush at the lead locomotive-wall interface stops at just over 0.1 seconds, as suggested it should by Figure 9 . The maximum crush of the lead end of the lead locomotive is just over $2 \frac{1}{2}$ feet. The lead end of the tender has reached maximum crush at about 0.25 seconds, at just under $4 \frac{1}{2}$ feet. The trail end of the tender reaches maximum crush at about 0.45 seconds, at just under $43 / 4$ feet. With crush at both ends, the overall reduction in length of the tender is over 9 feet.

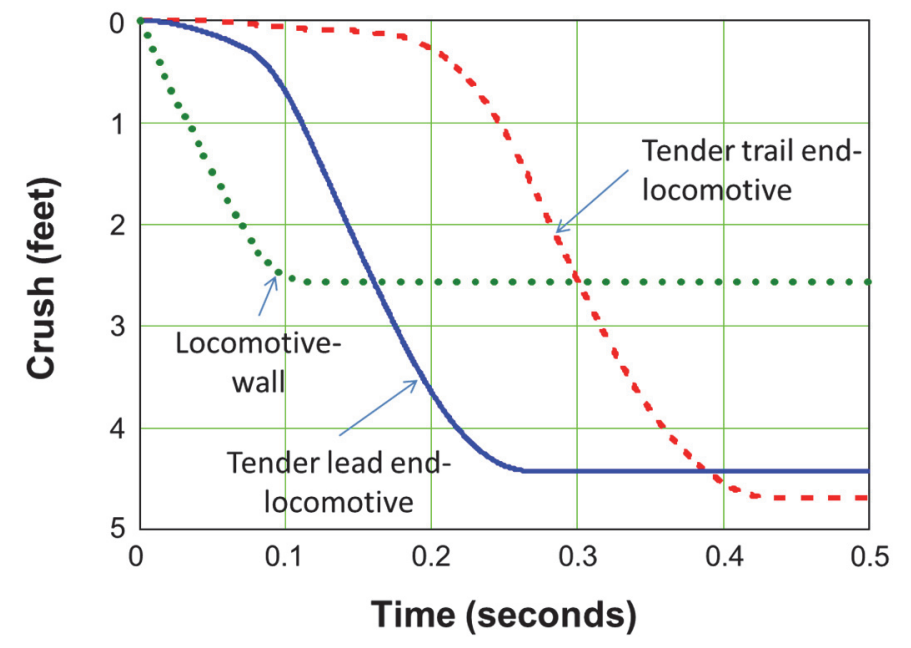

Fig. 10. CRUSH TIME HISTORIES FOR EQUIPMENT IN TRAIN-TO-TRAIN COLLISION SCENARIO

The reduction in tender length is associated with retraction of the pushback couplers, crush of the deformable anti-climbers, and crush of the primary energy absorbers. The tender trail end crush zone is fully exhausted, and the lead crush zone has modest additional capacity. The extent of crush for each interface is schematically illustrated in Figure 11. The underframe/tank remain essentially intact, as the crippling strength of the underframe/tank has not been exceeded. The peak force acting on the tender underframe/outer tank is 3,200 kips from the trailing locomotive, below its capacity of 4,000 kips. The locomotive anti-climber and draft gear box are crushed to the

This material is declared a work of the U.S. Government and is not subject to copyright protection in the United States. Approved for public release; distribution is unlimited. 
breastplate at the locomotive-wall interface. The lead locomotive underframe is crushed just enough to cripple. The extent of locomotive crush is not illustrated in Figure 11.

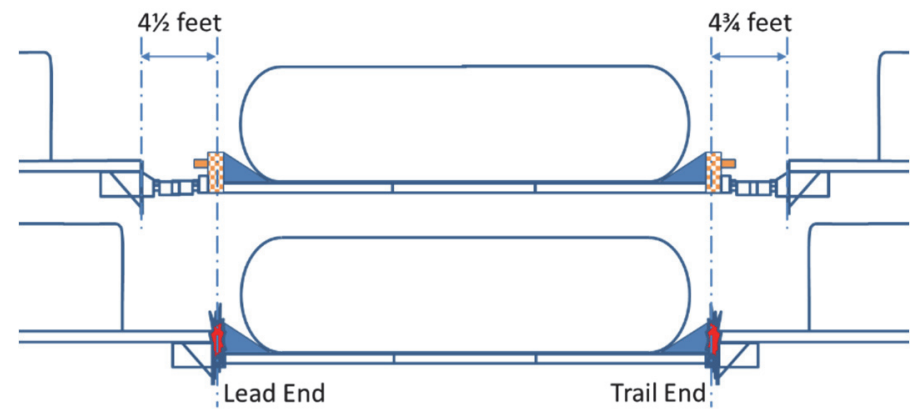

Fig. 11. EXTENT OF TENDER-LOCOMOTIVE CRUSH IN TRAIN-TO-TRAIN COLLISION SCENARIO

In the simulation, the lead end of the locomotive absorbs about 7.5 million $\mathrm{ft}-\mathrm{lbs}$, somewhat more than its initial kinetic energy of 7.0 million ft-lbs. This additional energy absorption slows the trailing equipment by about $1 \mathrm{mph}$, as shown in Figure 9. The lead end of the tender absorbs 5.3 million $\mathrm{ft}-\mathrm{lbs}$, and the trail end absorbs 6.1 million ft-bs; 6.6 million ft-lbs is needed to cripple the tender underframe/tank.

\section{COUPLING PERFORMANCE}

The AAR recommends that coupling be done at speeds no more than $4 \mathrm{mph}$. The one-dimensional lumped-parameter coupling dynamics model is shown in Figure 12. This model was use to estimate peak force as a function of coupling speed. The weight of the cars and combined weight of the couplers and yokes are needed for input, as well as the stiffness of the draft gear. The locomotive is initially moving, and the tender is initially standing. The couplers are assumed to couple instantaneously, so that the velocity of the couplers and yokes at the start of the simulation is half of the locomotive velocity. For a given locomotive initial velocity, results from the model include draft gear force as a function of time. Simulations were made for locomotive-to-locomotive coupling, as well as for locomotive-to-tender coupling.

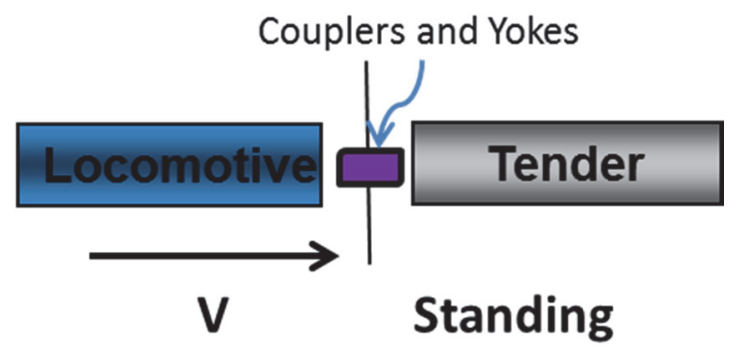

Fig. 12. ONE-DIMENSIONAL DYNAMIC COUPLING MODEL

The draft gear supplier rates NC-390 draft gear at 1,000 kips force and 35.5 thousand ft-lbs energy absorption at 1.43 inches of displacement [26]. The locomotive underframe is designed to sustain 1,000 kip static compressive load on the line of draft without permanent deformation [3], however, it does deform elastically approximately 0.75 inch [27] under such load. The underframe acts as a spring in series with the draft gear, so at 1,000 kips the total deflection is just under 2.25 inches. The design trigger load for the pushback coupler is 1,200 kips, which exceeds both the rated capacity of the draft gear and the static design capacity of the locomotive underframe. Figure 14 shows peak draft gear force as a function of coupling speed for a locomotive coupling with a tender and for a locomotive coupling with a locomotive.

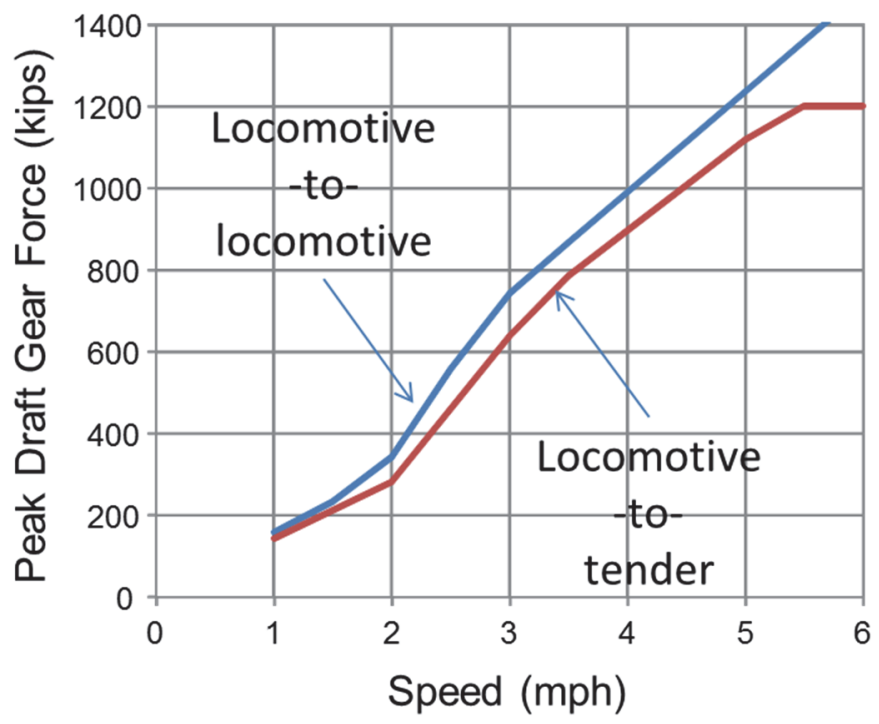

\section{Fig. 13. PEAK DRAFT GEAR FORCE AS A FUNCTION OF COUPLING SPEED}

For a 4 mph coupling speed, a peak force of 900 kips is expected for locomotive-to-tender coupling. A speed of nearly $5.5 \mathrm{mph}$ is needed to produce a load of 1,200 kips and trigger the pushback coupler. For a $4 \mathrm{mph}$ coupling speed, a peak force of nearly 1,000 kips is expected for locomotive-to-locomotive coupling. This force equals the draft gear's rated dynamic capacity and the design static load of the locomotive underframe. These results are moderately sensitive to the bottoming stiffness of the combined draft gear and underframe. Lower bottoming stiffness will result in lower loads for a particular coupling speed. Elastomeric elements, such as locomotive draft gear, tend to exhibit viscous damping behavior, which will also tend to lower peak loads for a given coupling speed. Viscous damping has not been included in the model.

\section{TECHNICAL BASIS FOR ALTERNATIVE DESIGN STANDARD FOR TENDER CRASHWORTHINESS}

Table 1 summarizes the functions, features, and key requirements associated with the proposed design strategy. The crashworthiness foundation is provided by the underframe/outer tank, which supports all of the other features. The load path is managed by the pushback coupler, deepened bellmouth, and deformable anti-climber. Distributed energy absorption is provided by the primary energy absorber in combination with any energy absorption capacity the pushback coupler and the deformable anti-climber might have. Simplified analysis results indicate that a tender design incorporating all of these features meets the dynamic requirements of the train-to-train collision scenario under discussion by the TAG.

This material is declared a work of the U.S. Government and is not subject to copyright protection in the United States. Approved for public release; distribution is unlimited. 
Table 1. Summary of Functions, Features, and Key Requirements

\begin{tabular}{|l|l|l|}
\hline Function & Feature & Key Requirements \\
\hline Foundation & $\begin{array}{l}\text { Underframe } \\
\text { /outer tank }\end{array}$ & $\begin{array}{l}\text { Crippling strength of } 4.5 \text { million lbs, for load applied at anti- } \\
\text { climber height } \\
\text { Sufficient to transfer load from lead to trail locomotive when } \\
\text { energy absorbing features are exhausted }\end{array}$ \\
\hline $\begin{array}{l}\text { Load Path } \\
\text { Management }\end{array}$ & $\begin{array}{l}\text { Pushback } \\
\text { Coupler }\end{array}$ & $\begin{array}{l}\text { Trigger load of } 1.2 \text { million lbs } \\
\text { Initiates before override and lateral buckling } \\
\text { Does not initiate for } 4 \text { mph coupling }\end{array}$ \\
\hline & $\begin{array}{l}\text { Enlarged } \\
\text { Bellmouth }\end{array}$ & $\begin{array}{l}\text { Accommodates coupled tender and locomotive couplers, } \\
\text { enabling tender and locomotive end structures to engage }\end{array}$ \\
\hline & $\begin{array}{l}\text { Tender anti- } \\
\text { climber }\end{array}$ & $\begin{array}{l}\text { Distributes load over wide area } \\
\text { Maintains lateral and vertical load capacity as it crushes } \\
\text { Capable of conforming to many locomotive designs }\end{array}$ \\
\hline Energy & $\begin{array}{l}\text { Primary } \\
\text { energy } \\
\text { absorption }\end{array}$ & $\begin{array}{l}\text { Peak crush force no more than } 3.0 \text { million Ibs } \\
\text { Energy absorption capacity of at least } 6.0 \text { million ft-lbs } \\
\text { In combination with the pushback coupler and deformable } \\
\text { anti-climber }\end{array}$ \\
\hline
\end{tabular}

The key requirements enumerated in Table 1 could potentially be used as the basis for a design standard alternative to the dynamic train-to-train collision scenario-based performance standard. Such a tender crashworthiness standard might have a similar form to AAR S-580 for locomotive crashworthiness. Rather than detailed computer simulation of the locomotive and tender behavior in the prescribed scenario, less complex evaluations would be needed to show that each and all of the five features met its key requirements.

\section{SUMMARY AND NEXT STEPS}

Research is being conducted to support the development of effective natural gas fuel tender crashworthiness standards. This research is sponsored by FRA's Office of Research, Development, and Technology. This research is being conducted cooperatively with the AAR and research results are being shared with the AAR's NGFT TAG. The TAG is developing safety and interchange standards for LNG tenders. In developing its standards, the TAG is also considering additional information and other research, beyond what is discussed in this paper.

This paper discusses modifying a DOT 113 tank car design with five CEM features: strong underframe, pushback coupler, deepened bellmouth, deformable anti-climber, and primary energy absorber. Simplified analysis results indicate that these features allow the modified design to meet the requirements of the dynamic train-to-train collision scenario under discussion by the TAG. Key design requirements for each and all of the five features could potentially be used as the basis for a design standard; however, engineering design, detailed analysis, and test efforts are likely to be essential to develop CEM features for LNG tenders that are service and crashworthiness compatible with freight locomotives.

Pushback couplers are unique among the five features, in that they are used both in service and in collision conditions, and there is tension between the service requirements and collision requirements. The simplified analysis results presented in this paper suggest that the competing needs of service and crashworthiness can be balanced. Testing to assure that this balance is achievable would increase confidence in such features working both in service and in accidents. Comparing measured loads during service of conventional and prototype pushback couplers could help assure that pushback couplers do not unintentionally trigger under service conditions.
Anti-climbers and primary energy absorbers are used only during collisions. Deformable anti-climbers and primary energy absorbers designed for freight service on LNG tenders could be destructively tested to measure deformation behavior. Comparison of test measurements to analysis predictions would increase confidence in the performance of these features in accident conditions.

The strong underframe is also used in service and in collision conditions, but the service and crashworthiness requirements are congruent. Non-destructive tests can be performed on tender underframe/outer tank, and the results extrapolated with detailed models to determine underframe crippling strength. Combined test and analysis can be used to assure a sound foundation of support for the other CEM features.

\section{ACKNOWLEDGMENTS}

This work was done as part of the Federal Railroad Administration's Equipment Safety Research Program. Melissa Shurland is the FRA's Program Manager and Kevin Kesler is the Chief, Equipment and Operating Practices Division, Office of Research, Development, and Technology. The author appreciates the efforts of Steve Clay, MP\&E Specialist, FRA Office of Safety for providing information on the Two Harbors accident. The author thanks Dr. Steven Kirkpatrick, Principal Engineer, ARA, for helping to smoothly coordinate industry and government research activities.

\section{REFERENCES}

[1]. Iden, M., "Liquefied Natural Gas (LNG) as a Freight Railroad Fuel: Perspective from a Western U.S. Railroad," American Society of Mechanical Engineers, Paper No. RTDF2012-9409, October 2012.

[2]. 49 CFR Part 229, 234, 235, et al. Positive Train Control Systems; Final Rule, Federal Register, Vol. 75, No. 10, January 15, 2010.

[3]. Association of American Railroads, AAR S-580 Standard, "Locomotive Crashworthiness Requirements," adopted December 2004, revised 2008.

[4]. Association of American Railroads, AAR S-5506 Standard, "Performance Requirements for Diesel Electric Fuel Tanks," Adopted as a Recommended Practice: 1995; Upgraded to Standard: 2001.

[5]. 49 CFR Part 216 et al., Passenger Equipment Safety Standards; Final Rule, Federal Register, Vol. 64, No. 91, May 12, 1999.

[6]. 49 CFR Parts 229 and 238 Locomotive Crashworthiness; Final Rule. Federal Register, Vol. 71, No. 124, June 28, 2006.

[7]. Code of Federal Regulations, Title 49, Appendix F to Part 238-Alternative Dynamic Performance Requirements for Front End Structures of Cab Cars and MU Locomotives. Federal Register, Vol. 75, No. 5, January 8, 2010.

[8]. EN 12663, Railway applications - Structural requirements of railway vehicle bodies, Ref. No. EN 12663-1:2010-03

[9]. EN 15227, Railway Applications-Crashworthiness Requirements for Railway Vehicle Bodies, Ref. No. prEN 15227:2007:E.

[10].Tyrell, D., "Liquefied Natural Gas Tender Crashworthiness Research," American Society of Mechanical Engineers, Paper No. JRC2015-5815, March 2015. 
[11].Kirkpatrick, S.W., Northrup, C., "Crashworthiness and Puncture Protection Analyses of LNG Tenders," American Society of Mechanical Engineers, Paper No. JRC20155812, March 2015.

[12]. National Transportation Safety Board, "Collision of Two Canadian National Railway Freight Trains near Two Harbors, Minnesota on September 30, 2010," NTSB/RAR13/01/SUM, February 12, 2013.

[13].Carolan, M., "Evaluation of Occupant Volume Strength in Conventional Passenger Railroad Equipment," Tufts University Master's Thesis, May 2008.

[14].Tyrell, D.C., Perlman, A.B., "Evaluation of Rail Passenger Equipment Crashworthiness Strategies," Transportation Research Record No. 1825, pp. 8-14, National Academy Press, 2003.

[15].Mayville, R., Stringfellow, R., Johnson, K., Landrum, S., "Crashworthiness Design Modifications for Locomotive and Cab Car Anticlimbing Systems," U.S. Department of Transportation, DOT/FRA/ORD-03/05, February 2003.

[16].Tyrell, D., Jacobsen, K., Martinez, E., "A Train-to-Train Impact Test of Crash Energy Management Passenger Rail Equipment: Structural Results," American Society of Mechanical Engineers, Paper No. IMECE2006-13597, November 2006.

[17].Priante, M., Martinez, E., "Crash Energy Management Crush Zone Designs: Features, Functions, and Forms," Proceedings of the 2007 ASME/IEEE Joint Rail Conference \& Internal Combustion Engine Spring Technical Conference, JRCICE2007-40051, March 2007.

[18].Smith, K., "Westport delivers first LNG tender to EMD," Railway Age, April 11, 2014.

[19].Llana, P., Stringfellow, R., Mayville, R., "Finite Element Analysis and Full-Scale Testing of Locomotive Crashworthy Components," American Society of Mechanical Engineers, Paper No. JRC2013-2546, April 2013.

[20].Llana, P., Stringfellow, R., "Preliminary Finite Element Analysis of Locomotive Crashworthy Components," American Society of Mechanical Engineers, Paper No, RTD2011-67006, September 2011.

[21].Llana, P., Stringfellow, R., "Preliminary Development of Locomotive Crashworthy Components," American Society of Mechanical Engineers, Paper No. JRC2011-56104, March 2011.

[22].Chatterjee, S., Carney, J., "Passenger Train Crashworthiness - Primary Collisions," Transportation Research Record 1531, Transportation Research Board, 1996.

[23].Mayville, R.A., Johnson, K.N., Stringfellow, R.G., Tyrell, D.C., "The Development of a Rail Passenger Coach Car Crush Zone," ASME/IEEE Paper No. ASME RTD 20031653, April 2003

[24].Scholes, A., and Lewis, J., 1993, "Development of Crashworthiness for Railway Vehicle Structures", Proceedings of the Institute of Mechanical Engineers, Vol. 207 Part F: Journal of Rail and Rapid Transit.

[25].Lacôte, F., Cléon, L.-M., Lagneau, H., Dannawi, M., Demonsant, E., Wiart, A., 1993, "Les Tolérances à la Collision Des Matérials Ferroviaires," Revue générale des chemin de fer, Gauthier-Villars.
[26].WABCO, National Rubber Cushioned Draft Gear Types NC-390 \& NC391, Sketch No. DG-690207, February 2, 1969.

[27].Mayville, R.A., Stringfellow, R.G., Rancatore, R.J., Hosmer, T.P., "Locomotive Crashworthiness Research, Volume 1: Model Development and Validation," DOT/FRA/ORD-95/08.1, 1995.

[28].Blader, F. B., “A Review of Literature and methodologies in the Study of Derailment Caused by Excessive Forces at the Wheel/Rail Interface", Association of American railroads, Report R-717, 1990.

\section{APPENDIX A: STRONG FOUNDATION}

The tender underframe/outer tank needs to support the loads from the pushback coupler, anti-climber, and primary energy absorber without crippling. When the crushable elements are all exhausted, the tender underframe/outer tank also has to transmit load from the leading locomotive to the trailing locomotive. This load, the transmission of load from locomotive to locomotive when all of the crushable elements are exhausted, is the highest load expected for the tender underframe.

One way to choose the strength of the tender underframe is to have it be as strong as a locomotive underframe for the same loading condition. The crippling strength of a locomotive underframe varies with the location of the applied load. The locomotive underframe can support the greatest load when the load is applied in-line with the underframe neutral axis. When the load is applied away from the neutral axis, at the coupler striker plate for example, the load required to cripple the underframe is reduced. This reduction in crippling load is owing to the moment created by applying the load away from the neutral axis [27].

Figure 14 shows longitudinal load as a function of crush for two different load application points on the locomotive underframe, at the neutral axis and at the striker. As can be seen in the figure, about 10,000 kips is needed to cripple the locomotive underframe when the load is applied to the neutral axis. When the load is applied to the striker plate, the magnitude needed to cripple the locomotive underframe is reduced to 3,000 kips. When the load is applied at the location where the tender anti-climber is expected to apply load, then the locomotive underframe crippling strength is interpolated to be 4,500 kips.

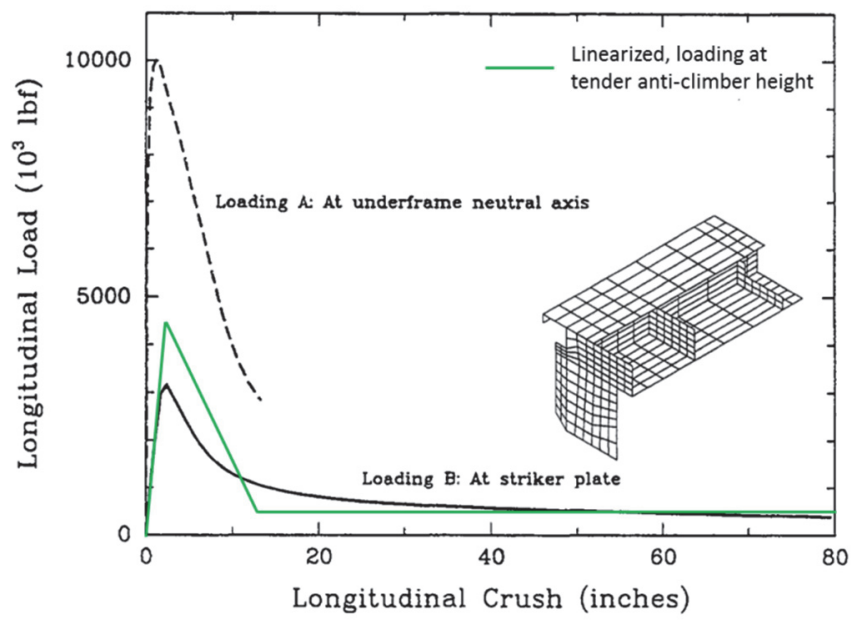

Fig. 14. LOCOMOTIVE UNDERFRAME CRIPPLING STRENGTH [27]

9

This material is declared a work of the U.S. Government and is not subject to copyright protection in the United States. Approved for public release; distribution is unlimited. 
Designing the tender underframe to have a crippling strength of at least 4,500 kips allows the tender underframe to be as strong as the locomotive underframe for the target line of load application. Implicit in this approach is the assumption that the neutral axes of the locomotive and tender are at two different heights.

\section{APPENDIX B: PUSHBACK COUPLER TRIGGER LOAD}

The force at which the pushback coupler starts to retract, the trigger load, defines when the entire mechanism starts to function. None of the other features come into play until the pushback coupler is retracted. The trigger load is selected to be low enough to inhibit override and lateral buckling and high enough to allow coupling of the car according to AAR practices.

In conventional coupler and draft gear arrangements, override and lateral buckling may occur when the longitudinal load becomes sufficiently large. The longitudinal forces needed for incipient override and lateral buckling can be estimated from a quasi-static balance of the forces acting on an initially perturbed car. Figure 15 illustrates the initial lateral and vertical perturbations chosen for the trigger load analyses.
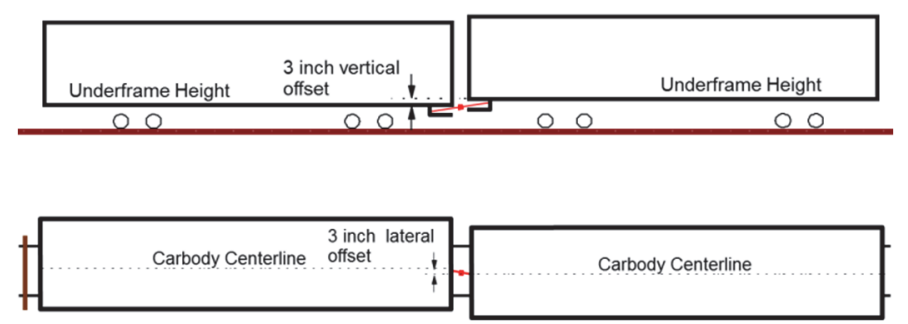

Fig. 15. SCHEMATIC OF PROPOSED LOCOMOTIVE PRIMARY ENERGY ABSORBER DESIGN APPROACH

Misalignment between cars occurs owing to imperfections in the track, imperfections in the equipment, and equipment suspension travel. In Class 5 track, track alignment variations of up to $3 / 4$ inch, gauge variations of up to $1 \frac{1}{2}$ inches, and profile variations of $1 \frac{1}{4}$ inch offset from a 62 foot chord are all permitted. Larger variations are allowed for lower classes of track. Wheel tread wear of up to $1 \frac{1}{2}$ inches and flange wear of up to $1 / 2$ inch is allowed. Rail suspensions typically have about 2 inches of vertical travel and 1 inch of lateral travel. 3 inches of lateral offset and vertical offset between cars are taken to be reasonably severe cases; they are roughly half of the most extreme offsets between cars that may be expected in service.

Figure 16 shows a free-body-diagram of a tender for estimating conditions needed for incipient override. Vertical unloading of the front truck is taken as the precursor to override. There is a vertical load acting at the lead-end buff stops and no vertical load acting on the trailing-end buff stops. For an empty car weight of 150 kips, 64 kips of upward vertical load acting at the lead buff stops is sufficient to unload the front truck.

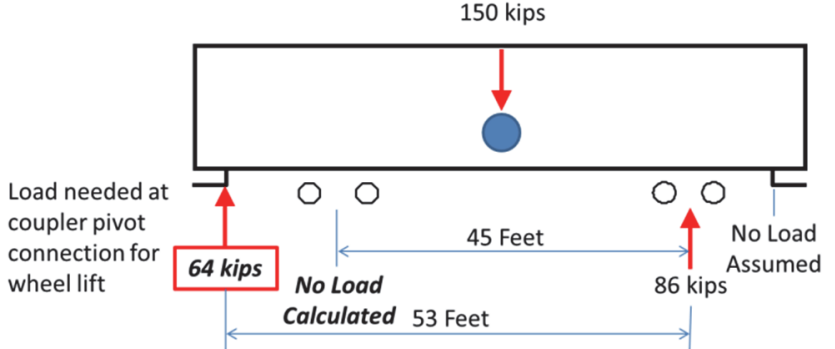

\section{Fig. 16. QUASI-STATIC VERTICAL LOAD SUFFICIENT FOR INCIPIENT OVERRIDE}

Figure 17 shows a free-body-diagram of a tender for estimating conditions needed for incipient derailment. A truck lateral-to-vertical $\mathrm{L} / \mathrm{V}$ force ratio of 0.8 is taken as the precursor to derailment. Derailment can occur for a number of reasons, including wheel climb, rail rollover, and track panel shift. Generally, keeping wheel, truck, and truck side L/V ratios lower than about 0.8 provides some assurance that derailment is not likely to occur [28]. The longitudinal wheel forces are assumed to balance any moments arising from lateral forces. For an empty car weight of 150 kips, 60 kips of lateral load acting at the lead buff stops is sufficient to cause a truck $\mathrm{L} / \mathrm{V}$ of 0.8 .

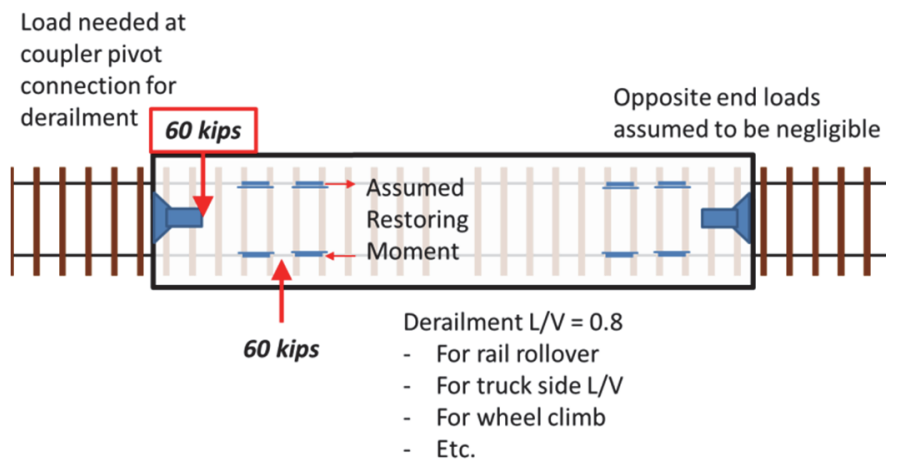

Fig. 17. QUASI-STATIC LATERAL LOAD SUFFICIENT FOR INCIPIENT BUCKLING

Figure 18 shows a free-body-diagram of two coupled tightlock couplers. The pivot ends of the couplers are offset by 3 inches, the same distance as the car end offsets illustrated in Figure 15. The lateral loads acting at each pivot point are both 60 kips. The longitudinal load carried by the couplers is then 1,200 kips.

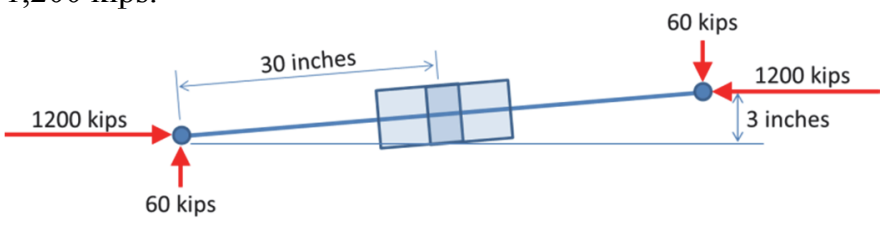

Fig. 18. QUASI-STATIC LONGITUDINAL LOAD SUFFICIENT FOR INCIPIENT BUCKLING

With a trigger load of 1,200 kips, a pushback coupler can inhibit override and lateral buckling for an unloaded tender coupled to a locomotive. Override or lateral buckling may potentially still occur under some conditions, such as for offsets greater than 3 inches between the locomotive and tender. Inertial loads, which have been neglected in these calculations, will tend to favor triggering the pushback coupler over override and buckling.

10

This material is declared a work of the U.S. Government and is not subject to copyright protection in the United States. Approved for public release; distribution is unlimited. 